\title{
The Harmful Effects of Non Alcoholic Drugs on Driving: It's Time to Use Technology to Enforce the Law
}

\section{R. Graham ${ }^{1}$, Bruce Davies ${ }^{2}$ and Julien S Baker ${ }^{3 *}$}

${ }^{1}$ Institute for Health, Medical Science and Society, Glyndwr University, Wrexham, LL11 2AW, UK

${ }^{2}$ Health and Exercise Science Research Unit, School of Science, University of Glamorgan, Pontypridd, South Wales, UK

${ }^{3}$ Institute for Clinical Health and Exercise Science, Exercise Science Research Laboratory, School of Science, Faculty of Science and Technology, University of the West of Scotland, Hamilton, Lanarkshire, Scotland, ML3 OJB, UK

Professional sports-persons and an increasing number of amateur body builders self-administer performance and image enhancing drugs (PIEDs), which increase their muscle mass, strength and sporting performance $[1,2]$. This contravenes the ethics of fair play and the law.

Certain types of the PIEDs which are androgenic-anabolic steroids (AAS) are controlled drugs (CDs) and considered drugs of abuse by the Home Office. In 1996 their classification was changed from prescription only medicines (POMs) to CDs, to account for their addictive nature.

AAS are still the most abused doping agent in sport, and accounted for the greatest number of adverse analytical findings in 2011 [3].

They have a significant impact on the stress responsive hypothalamicpituitary-adrenal (HPA) axis. An abnormal response to stress may mediate the development or maintenance of addictive conditions. The abuse of such drugs also has an impact on the endogenous opioid system, and the dopaminergic system (neurochemicals in the brain, which encourage continued use). Each of these systems is implicated in the mediation of aggressive behaviour [4].

General behaviour may also be adversely affected. Pope and Katz $[5,6]$ summarised the more extreme psychiatric effects of AAS abuse and Clark and Henderson [7] have identified behavioural responses to AAS.

The common psychological effects of increased confidence and unintended aggression are summarised by Daly et al. [8], Hall et al. [9] and Graham et al. [10]. The effects of AAS abuse, causing hostility has been demonstrated in monozygotic twins. The study found high levels of aggression, hostility, anxiety and paranoid ideation in the twins who used AAS. The non-user twins showed no deviation from their initial status. The use of AAS induced several important psychiatric changes in monozygotic twins which were not present in the twins who did not use AAS [11].

There is substantial evidence suggesting that the use of such drugs will influence behaviour, and therefore, motor vehicle driving awareness.

Under the present legislation AAS, are controlled drugs 'Class C' (The Misuse of Drugs Act, 1971), and defined as 'Schedule 4 drugs' (The Misuse of Drugs Regulations, 2001). Such drugs are excepted from prohibition on possession by any person for administration to oneself by virtue of part II of Schedule 4 of the Misuse of Drugs Regulations 2001.

The man travelling on public transport is not committing an offence by possessing these drugs for personal use.

The same cannot be said for a professional sportsperson who face the threat of expulsion from the governing bodies of their sport.

The 1988 Road Traffic Act section 5(1) (b) and section 4(1) are simplistic with respect to driving with excess alcohol or while unfit through drink or dugs respectively. The Act states 'a person who, when driving or attempting to drive a motor vehicle on a road or a public place is unfit to drive through drink or drugs is guilty of an offence'.
Presently, the policing authorities do not take full advantage of the testing procedures available, for drug detection.

A simple urinalysis will detect the acute ingestion of most performance enhancing drugs which could compromise performance at the wheel.

The British courts will accept hair analysis in "family law", as proof of alcohol and recreational street drug abuse, and are dispensing justice following identification of misuse [12].

They are not using such sophisticated forensic analysis to identify doping, whilst in control of road traffic vehicles.

To date, the World Anti-Doping Agency (WADA), have not adopted hair analysis as proof of doping in sport.

Urinalysis and blood analysis will identify acute abuse, but hair analysis identifies chronic abuse over an extended time.

Enforcement authorities currently use breathalysers in order to successfully confirm whether a person is over the legal limit of alcohol. They do not appear to be taking advantage of technological equipment that can successfully confirm whether a person is under the influence of other recreational drugs of abuse.

They rely on the suspected person carrying out specific exercises in order for them to evaluate whether they believe the person to be under the influence of drugs whilst in charge of a vehicle.

The different exercises they use to ascertain whether or not a person is under the influence of alcohol or drugs are:

"Ask that the suspect stands up, tilts his/her head backwards closing the eyes and counting to 30 .

Standing on one leg and changing between the right and left leg.

Ask the suspect to touch his nose a number of times and then changing between his left and right hand."

The cost to the public purse in using this crude methodology is significantly cheaper than urinalysis or blood analysis.

In 2011, 22\% of those killed in road traffic accidents (RTAs) in the UK had illegal drugs in their bloodstream, producing untold personnel

*Corresponding author: Professor Julien S Baker, Institute for Clinical Health and Exercise Science, Exercise Science Research Laboratory, School of Science, Faculty of Science and Technology, University of the West of Scotland, Hamilton, Lanarkshire, Scotland, ML3 OJB, UK, E-mail: jsbaker@uws.ac.uk

Received May 17, 2012; Accepted May 19, 2012; Published May 21, 2012

Citation: Graham MR, Davies B, Baker JS (2012) The Harmful Effects of Non Alcoholic Drugs on Driving: It's Time to Use Technology to Enforce the Law. J Sports Med Doping Stud 2:e111. doi:10.4172/2161-0673.1000e111

Copyright: (c) 2012 Graham MR, et al. This is an open-access article distributed under the terms of the Creative Commons Attribution License, which permits unrestricted use, distribution, and reproduction in any medium, provided the original author and source are credited. 
and family tragedies in addition to the enormous cost to the tax payer [13].

There is a limit on alcohol before it is deemed illegal to drive.

There is zero tolerance with recreational street drugs. If any trace of drug is found in a suspect's system, he or she is deemed to be unfit to drive. This can also include some prescription drugs that have psychotropic side effects.

It is accepted that chronic use can affect the psyche in respect of the parental care of a child and judgements are made on the fitness of an individual to be a parent, with the use of modern technology. However, we are not applying this technology to decide a person's ability to be in control of machinery nor motor vehicles.

Drug testing in the United Kingdom is permissive. National Rail train drivers are only required to submit to random drug testing.

The present random testing in professional sports, especially team-sports, is laissez-faire. Multiple loopholes can be exploited to evade a positive test. If such cheats had to continually look over their shoulders when they got behind the wheel of their vehicles, it would develop considerable apprehension with regard to drug misuse. The enforcement authorities, the police and WADA must progress with the pace of technology, irrespective of monetary cost.

Government support for forensic analysis has already been axed. People forget that this was how the killers of Stephen Lawrence were identified, convicted and brought to justice.

Government grants must be made available to enhance the present research knowledge relating to the effects, and detection, of driving under the influence of mood changing drugs other than alcohol.

\section{References}

1. Kicman AT (2008) Pharmacology of anabolic steroids. Br J Pharmacol 154: 502-521.
2. Graham MR, Davies B, Grace FM, Kicman A, Baker JS (2008) Anabolic steroid use: Patterns of use and Detection of doping. Sports Med 38: 505-525.

3. http://www.wada-ama.org/en/Science-Medicine/Anti-Doping-Laboratories/ Laboratory-Statistics.

4. Schlussman SD, Nyberg F, Kreek MJ (2002) The effects of drug abuse on the stress responsive hypothalamic-pituitary-adrenal axis and the dopaminergic and endogenous opioid systems. Acta Psychiatr Scand Suppl : 121-124.

5. Pope HG Jr, Katz DL (1988) Affective and psychotic symptoms associated with anabolic steroid use. Am J Psychiatry 145: 487-490.

6. Pope HG Jr, Katz DL (1990) Homicide and near-homicide by anabolic steroid users. J Clin Psychiatry 51: 28-31.

7. Clark AS, Henderson LP (2003) Behavioral and physiological responses to anabolic-androgenic steroids. Neurosci Biobehav Rev 27: 413-436.

8. Daly RC, Su TP, Schmidt PJ, Pagliaro M, Pickar D, et al. (2003) Neuroendocrine and behavioral effects of high-dose anabolic steroid administration in male normal volunteers. Psychoneuroendocrinology 28: 317-331.

9. Hall RC, Hall RC, Chapman MJ (2005) Psychiatric Complications of Anabolic Steroid Abuse. Psychosomatics 46: 285-290.

10. Graham MR, Davies B, Kicman A, Cowan D, Hullin D, et al. (2007) Recombinant human growth hormone in abstinent androgenic-anabolic steroid use: Psychological, endocrine, and trophic factor effects. Curr Neurovasc Res 4: 9-18.

11. Pagonis TA, Angelopoulos NV, Koukoulis GN, Hadjichristodoulou CS, Toli PN (2006) Psychiatric and hostility factors related to use of anabolic steroids in monozygotic twins. Eur Psychiatry 21: 563-569.

12. Paul R, Kingston RG, Tsanaclis L, Berry A, Guwy A (2008) Do drug users use less alcohol than non-drug users? A comparison of ethyl glucuronide concentrations in hair between the two groups in medico-legal cases. Forensic Sci Int 176: 82-86.

13. http://www.thesite.org/drinkanddrugs/drugsafety/usingdrugs/ howdrugsaffectdriving 